\title{
Nostalgic Scents of Childhood and Psychological Implications
}

\author{
Eirini Petratou
}

Panteion University

\begin{abstract}
This study examines the effects of olfactory nostalgia, more specifically how nostalgic scents that evoke nostalgia can have psychological effects. The test participants sampled five childhood scents, rating each scent as to the extent in which they were familiar and elicited nostalgia and positive emotions. The research found that a scent linked with childhood was considered the most familiar but also the most nostalgic, eliciting higher self-esteem, social connection, optimism and inspiration. Our research findings on olfaction contributes to the existing small body of experimental research on nostalgic scents and facilitate the understanding of the psychological implications, triggers and affective response linked with scent-evoked nostalgia.
\end{abstract}

Keywords: nostalgia; olfaction; memory; scent; positive emotions 